\title{
O IDEB COMO PARÂMETRO DE QUALIDADE DA EDUCAÇÃO BÁSICA NO BRASIL: algumas preocupações
}

\author{
THE IDEB AS BASIC EDUCATION QUALITY PARAMETER IN BRASIL: some con- \\ cerns

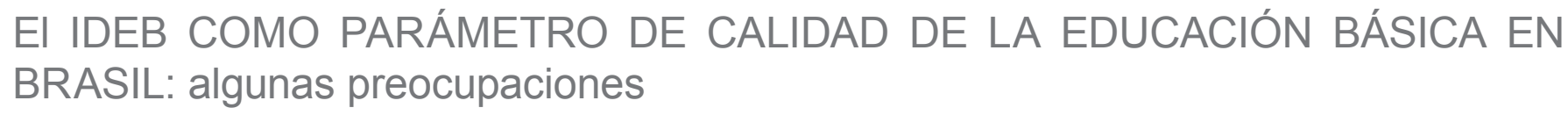

Luiz Carlos Gesqui

Pós-Doutor em Educação pela Pontifícia Universidade Católica de São Paulo (PUC-SP). Professor Titular do Mestrado Profissional em Educação da Universidade de Araraquara (UNIARA).

Igesqui@gmail.com

\begin{abstract}
RESUMO: A busca pela definição de elementos que estabelecessem padrões mínimos do que consistiria qualidade da educação básica nacional ocupou lugar de destaque no campo educacional brasileiro por décadas. Este artigo tem o objetivo de destacar que o Plano Nacional de Educação (PNE) 2014-2024 desestimula esta busca ao estabelecer legalmente o Índice de Desenvolvimento da Educação Básica (IDEB) como parâmetro de qualidade da educação básica nacional. Para desenvolver este argumento são analisadas, num primeiro procedimento, produções acadêmicas que antecedem o atual PNE e que têm por objeto de estudo desdobramentos do uso de indicadores estatísticos no campo educacional. Num segundo procedimento é analisada a meta 7 do atual PNE e algumas de suas estratégias cotejando-as com resultados de recentes pesquisas cujos objetivos se assemelham aos objetivos propostos pelas referidas estratégias. Os resultados das análises realizadas apontam para uma ampla desconsideração da produção acadêmica referente à qualidade da educação elaborada no período que antecede aprovação do atual PNE e que algumas práticas escolares cujos objetivos se assemelham aos objetivos propostos pelas estratégias analisadas tem produzido desdobramentos que não contribuem para a melhoria da qualidade da educação básica.
\end{abstract}

PALAVRAS-CHAVE: IDEB. PNE. Qualidade educacional. Educação básica.

ABSTRACT: The search for the definition of elements that establish minimum standards which would consist quality of the national basic education occupied a prominent place in the Brazilian educational field for decades. This article aims to highlight that the National Education Plan (PNE) 2014-2024 discourages this search to legally establish the Basic Education Development Index (IDEB) as a quality parameter of the national basic education. To develop this argument are analyzed in a first procedure, academic productions that precede the current PNE and who has study object the use of statistical indicators in the educational field. In a second procedure it has been analysed the goal 7 of the current PNE and some of their strategies comparing them with results of recent research whose objectives are similar to the objectives proposed by these strategies. The results of analyzes indicate a wide disregard of academic production related to the quality of the elaborate education in the period before approval of the current PNE and that some school practices whose goals are similar to those proposed by the strategies analyzed goals has produced outcomes that do not contribute to improving the quality of basic education.

KEYWORDS: IDEB. PNE. Educational quality. Basic education.

RESUMEN: La búsqueda por la definición de los elementos que establecen normas mínimas de indicaticvas de que consistiría en la educación básica nacional ocupó un lugar destacado en el campo de la educación brasileña durante décadas. Este artículo tiene como objetivo destacar que el Plan Nacional de Educación (PNE) 2014-2024 desestima esta busca por establecer legalmente el Índice de Desarrollo de la Educación Básica (IDEB) como parámetro de calidad de la educación básica nacional. Para desarrollar este argumento se analizan en un primer procedimiento, producciones académicas que preceden al PNE actual y que poseen objeto de estudio por el uso de indicadores estadísticos en el campo educativo. En un segundo procedimiento es analizada la meta 7 del PNE actual y algunas de sus estrategias comparándolas con los resultados de recientes investigaciones cuyos objetivos son similares a los objetivos propuestos por estas estrategias. Los resultados del análisis indican una gran desprecio de la producción académica relacionada con la calidad de la educación elaborada en el período antes de la aprobación del PNE actual y que algunas prácticas escolares cuyos objetivos son similares a los propuestos por las estrategias analizadas han producido resultados que no contribuyen a la mejoría de la calidad de la educación básica.

PALABRAS CLAVE: IDEB. PNE. Calidad de educación. La educación básica.

$\overline{\text { Artigo recebido em setembro de }} 2016$

Aprovado em novembro de 2016

Cad. Pes., São Luís, v. 23, n. 3, set./dez. 2016 


\section{1| INTRODUÇÃO}

Abordar qualquer um dos inúmeros temas pertinentes ao campo educacional brasileiro é uma tarefa complexa, visto que possibilitam inúmeras entradas, debates e discussões que compõem tal campo. Nas últimas décadas, entretanto, o tema referente à qualidade da educação básica nacional - em especial na escola pública - tem ocupado lugar de destaque nestas discussões e envolvido diferentes segmentos da sociedade, uma vez que, do leigo ao especialista, todos se consideram aptos a emitir opinião fundamentada sobre o tema e as justificativas para tal aptidão se estendem do simples fato de ter, no caso dos leigos, frequentado uma escola por muitos anos ou, no caso dos especialistas, por serem reconhecidamente conhecedores do tema.

Ao cenário exposto, brevemente, faz- se necessário acrescentar a longa busca acadêmica e legal pelo estabelecimento de padrões mínimos do que pode ser considerado qualidade da educação. Este artigo divide esta longa busca em dois (2) períodos: um período mais longo, que antecede a aprovação do atual Plano Nacional de Educação (PNE) com destaque para a indefinição acadêmica e legal sobre quais seriam os constituintes mínimos para se afirmar que a educação é de qualidade, ou não, e o período recente que se inicia com a aprovação do atual PNE e a definição legal de qualidade da educação descrita em sua meta sete (7) ao estabelecer o Índice de Desenvolvimento da Educação Básica (IDEB) como parâmetro oficial de qualidade da educação básica nacional.

O objetivo aqui é o de apresentar que, com a aprovação do PNE 2014-2024 (BRASIL, 2014) o IDEB desestimula a necessária continuidade de discussões acadêmicas e legais sobre o conceito de qualidade da educação básica nacional, uma vez que desconsidera as produções acadêmicas que antecedem o referido plano. Para desenvolver este argumento utilizo dois (2) procedimentos. No primeiro apresento um cenário que antecede o PNE 2014-2024 (BRASIL, 2014) com produções acadêmicas que dão ênfase à indefinição acadêmica e legal deste cenário e, no segundo, destaco, do referido plano, a meta 7 e algumas de suas estratégias, estabelecendo uma aproximação entre estas e as produções acadêmicas cujos objetivos se assemelham aos descritos na referida legislação.

As análises desenvolvidas ao longo dos procedimentos têm por referência as considerações apresentadas pelos autores das produções acadêmicas citadas e, em especial, as de Freitas (2007) no que se refere ao mascaramento da má qualidade educacional, o que considera Ravitch (2011)aoapresentar desdobramentos da utilização de indicadores estatísticos no campo educacional americano.

O texto está organizado de modo a situar, inicialmente, o problema da qualidade da educação básica nacional e sua relação com os indicadores estatísticos, e, em seguida, a apresentação dos procedimentos utilizados e algumas considerações.

\section{2 | A QUALIDADE DA EDUCAÇÃO BÁSICA NACIONAL E O USO DOS INDICADORES ES- TATÍSTICOS}

Para situarmos a questão da qualidade da educação básica nacional, em especial no que se refere à sua aferição por meio de indicadores estatísticos, é necessário, em um primeiro ponto, entendê-la como uma política pública educacional sendo que, neste artigo, toma-se por política educacional o conjunto de políticas públicas pertinentes ao tema educação e por políticas públicas, as ações desenvolvidas pelo Estado com o objetivo de garantir a efetivação de direitos cons- titucionais a todos.

No cenário mundial, as últimas décadas do século passado foram marcadas por grandes transformações na sociedade, uma vez que instituições sólidas foram desafiadas quanto à sua estrutura, organização e finalidades, principalmente em função da ampliação do acesso à informação e à comunicação. A esse conjunto de transformações chamou-se de globalização, cujo carro-chefe é o 
campo econômico que impacta significativamente os demais campos da sociedade. No cenário nacional, dadas determinadas condições, o Estado, que havia acabado de sair de um longo período de ditadura militar, desencadeia um conjunto de ações com o objetivo de se adaptar a essas transformações e ingressar no mundo globalizado. A esse conjunto de ações, em que a privatização de empresas estatais e a abertura da economia nacional ao capital estrangeiro são exemplos, dá-se o nome de reformas do Estado (OLIVEIRA, 2000).

Nesse contexto, no qual o campo educacional brasileiro é marcado por várias ações nos âmbitos nacional, estadual e municipal como os debates sobre Parâmetros Curriculares Nacionais PCN (BONAMINO; MARTÍNEZ, 2002), sobre as políticas de municipalização e descentralização da educação (SOUZA; FARIA, 2004), sobre o financiamento da educação (OLIVEIRA; ADRIÃO, 2007) e, finalmente, sobre as políticas de avaliação externa dos sistemas de ensino (BONAMINO; SOUZA, 2012), há que se destacar, no âmbito legal, a Constituição de 1988 (BRASIL, 1988) que estabelece a linha mestre da legislação educacional no país, a Lei de Diretrizes e Bases da Educação Nacional (LDBN) n 9.396 (BRASIL, 1996), fazendo emergir, que estabelece, de modo ampliado e com base na Constituição, as diretrizes da educação nacional e o atual Plano Nacional de Educação - PNE (BRASIL, 2014) com suas duzentas e cinquenta e quatro estratégias.

No âmbito internacional, a Conferência Mundial sobre Educação para Todos, ocorrida na Tailândia em 1990, pode ser considerada um marco na entrada incisiva do elemento econômico no campo educacional, uma vez que patrocinada pela Organização das Nações Unidas para a Educação, a Ciência e a Cultura (UNESCO), Fundo das Nações Unidas para a Infância (UNICEF), Programa das Nações Unidas para a Infância (PNUD) e Banco Mundial, referendada pelos governos de 155 países e baseada em um quadro estatístico com 100 milhões de crianças não alfabetizadas e mais de 900 milhões de analfabetos no mundo, determinava que os nove (9) países, entre eles o Brasil, com as maiores taxas de analfabetismo no mundo, estabelecessem metas e compromissos para o ano 2000, no intuito de alterar significativamente este quadro (SHIROMA; MORAES; EVANGELISTA, 2004). O estabelecimento de metas e compromissos no Brasil seguiu, principalmente por questões financeiras, as determinações do Banco Mundial.

Nesse aspecto, produções de Torres, de Coraggio e de Soares (TOMMASI; WARDE; HADDAD, 1996) alertavam que o Banco Mundial não exerce apenas o papel de financiar as reformas educacionais, mas também o de determinar as práticas a serem utilizadas para a execução dessas reformas, práticas essas baseadas principalmente em aspectos econômicos que buscam a eficiência do sistema educacional e, para tanto, desconsideram, entre outros, aspectos intra e extraescolares de cada unidade escolar. A eficiência do sistema educacional passa a ser aferida por meio de indicadores estatísticos e para tanto se inicia no Brasil, a partir de 1995, a elaboração e implantação de sistemas nacionais de avaliação cujo principal objetivo é o de produzir e aperfeiçoar esses indicadores.

A junção do estabelecimento de metas passíveis de mensuração objetiva a partir da busca de um sistema educacional eficiente concorreu para a elevação dos indicadores produzidos pelas avaliações educacionais em larga escala externas à escola e ao status de elemento determinante na proposição, implantação, acompanhamento, avaliação, continuidade ou encerramento de toda e qualquer política educacional, pois como expressa Carvalho (2001, p. 233) "as estatísticas, as taxas, os índices, os gráficos e as tabelas são cada vez mais tomados como sinônimo de verdade final e incontestável, como prova cabal desta ou daquela afirmação". A partir desta perspectiva, é possível inferir que discussões referentes aos objetivos e finalidades da educação, condições de formação e atuação docente ou atendimento a demandas específicas, sucumbiram - ou, na melhor das hipóteses, ocupam um plano secundário - frente ao determinante econômico.

Relacionando a esse conjunto de informações, é possível utilizar um artigo de Stephen Ball (2004) em que o autor apresenta alguns desdobramentos da inserção e priorização do uso de tecnologias 
de mercado no campo educacional, com ênfase para quatro (4) elementos: o Estado, o capital, o setor público e o cidadão. O Estado abandona seu papel de provedor e assume o papel de regulador das políticas públicas, uma vez que estabelece metas - no Brasil representado pelo Índice de Desenvolvimento da Educação Básica (IDEB) no campo educacional -, o qual possibilita dirigir a educação à distância, dissolver fronteiras entre o social e o econômico, estabelecer as parcerias públicas e privadas bem como de terceirizar mão de obra; o capital vislumbra, no campo educacional, a possibilidade de lucros expressivos, haja vista o tema educação ser elemento central na agenda da Organização Mundial do Comércio (OMC); o setor público, e o campo educacional, por conseguinte, foram invadidos pelos termos cultura de resultados, alvos, recompensas e sanções, transformando o trabalho educativo em trabalho de resultados em que o conhecimento do estudante se torna idêntico ao seu resultado em testes objetivos e padronizados.

Dadas às condições objetivas estabelecidas, resta para o cidadão acreditar nos indicadores, isto é, se os números são divulgados como positivos, mesmo que este não tenha o conhecimento mínimo de como tal indicador foi produzido ou a que corresponda. Contudo, cabe destacar o fato de se observar poucas críticas fundamentadas cientificamente a tais indicadores por parte dos profissionais da educação, porém, ainda assim, faz-se necessário descrever alguns fatores que contribuíram significativamente para que o cidadão, assim como a uma significativa parcela dos profissionais da educação acreditem que tais indicadores cumpram, de fato, aquilo a que se propõem, isto é, mensurem a qualidade da educação básica nacional e produzam informações que orientem políticas educacionais.

\subsection{Qualidade da educação básica nacional até o PNE 2014 - 2024}

Apresentar uma definição de qualidade educacional - o que não é o objetivo deste artigo - ou simplesmente um consenso entre legislação, acadêmicos, profissionais da educação ligados às escolas, órgãos propositores, órgãos multilaterais e sociedade é considerada uma tarefa complexa, visto que cada definição responde a determinadas condições, anseios ou simplesmente limitação de informações. Vários autores, porém, apresentam aspectos recorrentes na utilização do conceito de qualidade educacional, como o fato de ser considerado complexo, histórico, polissêmico e socialmente construído.

A qualidade de ensino é apresentada por Beisiegel (2006, p. 7) como "matéria de grande complexidade e sua discussão envolve amplo elenco de questões" dando pistas de que muitas dessas questões envolvem diferentes atores, com diferentes interesses que extrapolam o âmbito escolar. $\mathrm{Na}$ obra, o autor estabelece relações entre o que, em cada período histórico, é considerada qualidade educacional com diferentes acontecimentos, como os interesses eleitorais ou as discussões sobre projetos de educação para o Brasil. Todavia, destaca-se a advertência que faz quanto aos riscos de transformar em conceitos informações ou hipóteses não referendadas cientificamente. O estabelecimento de uma relação direta entre o ingresso das camadas populares na escola pública e a diminuição de sua qualidade é um exemplo.

No que se refere a uma efetiva discussão sobre qualidade educacional Dourado (2007) argumenta sobre a necessidade de que sejam consideradas como elementos fundamentais as condições sociais, culturais e econômicas referentes ao espaço social ocupado pela escola, bem como as obrigações do Estado relacionadas à definição, oferta e garantia de padrões de qualidade e igualdade de condições para o acesso e a permanência na escola. $\mathrm{O}$ autor define tais elementos como condições extraescolares. Da mesma forma, fundamentais, segundo o autor, são os elementos que apresentam como condições intraescolares, como a oferta de instalações gerais adequadas aos padrões de qualidade, a gestão e organização do trabalho escolar que priorizem o 
processo de ensino e aprendizagem com qualidade, as condições de trabalho dos docentes e as condições de acesso, permanência e desempenho escolar adequados aos alunos. Isto posto, tornam-se possíveis as hipóteses de que é arriscado analisar ou elaborar um indicador de qualidade educacional sem a consideração de ao menos algumas das condições - intra ou extraescolares citadas anteriormente; é arriscado afirmar que é de qualidade a educação oferecida por uma rede escolar ou por uma escola e, muito mais arriscado definir, nessas condições, políticas educacionais.

Igualmente importante é o aspecto destacado por Ramos (2010), ao alertar que em nossos dias, o maior desafio de uma educação de qualidade é o de assegurar aprendizagem adequada aos alunos e não apenas a oferta de vagas. Para tanto, afirma que, em nosso país, três (3) ações são fundamentais nesse sentido: eliminar o analfabetismo, ampliar, em muito, o financiamento da educação básica, e valorizar o docente. Segundo ele, estas ações promoverão a oferta de uma educação que atenda as demandas sociais. Quanto à oferta de vagas, Romualdo Oliveira (2007) afirma que o desafio da universalização do acesso, ao menos para a população de 7 a 14 anos, está próximo de ser superado, observado o aumento do número de matrículas nas últimas três (3) décadas.

A UNESCO afirma que qualidade educacional é um conceito com grande diversidade de significados, condicionados a fatores ideológicos e políticos e que variam de uma sociedade para outra (UNESCO, 2007). A considerarmos a diversidade de ações desenvolvidas pela UNESCO, o número de países atendidos e as diferentes culturas com as quais mantém contato, as variáveis ou critérios que utiliza para delimitar um conceito são muitas, o que permite inferir que a definição de um conceito, no caso o de qualidade educacional, deve considerar a grande diversidade de significados, condicionada a fatores ideológicos e políticos e que variam de uma escola para outra, de uma rede de ensino para outra, de um município para outro e assim sucessivamente, ou seja, é possível que critérios considerados indispensáveis para a aferição de qualidade em determinada escola sejam considerados irrelevantes em outro contexto.

Dourado e Oliveira (2009, p. 203) apresentam a escola como importante espaço de formação do indivíduo, porém, ao destacarem-na em seu aspecto de "espaço institucional de produção e disseminação, de modo sistemático, do saber historicamente produzido pela humanidade" evocam a necessidade de clareza quanto às dimensões e fatores a serem considerados para se discutir questões relativas à qualidade educacional. Para tanto, questionam quais práticas, políticas educacionais e fatores apontam para a construção de uma educação de qualidade, ou dito de outro modo, a constatação de quais características permite afirmar que determinada escola é de qualidade ou não? Quais os padrões mínimos para esta afirmação?

Os questionamentos levantados por tais autores são justificáveis. Romualdo Oliveira (2006) alerta para o fato de que nem a atual Constituição Federal (BRASIL, 1988) estabelece em que consistiria ou quais elementos integrariam um padrão mínimo de qualidade do ensino brasileiro, isto é, se não está claro para nenhum dos segmentos envolvidos o que deve ser considerado minimamente um ensino de qualidade, como atestar sua presença e oferta ou, ao menos, mensurá-lo? É oportuno, contudo, destacar o aspecto complicador de que, em função da inexistência de padrões mínimos de qualidade educacional, previstos legalmente, o mesmo não possa ser cobrado judicialmente por nenhum dos segmentos envolvidos.

Quanto à legislação educacional brasileira, Gusmão (2010) ao analisar as diferentes noções de qualidade educacional presentes em alguns documentos relacionados ao campo educacional brasileiro $^{1}$, encontra o termo qualidade citado em noventa (90) oportunidades e na maioria delas

\footnotetext{
${ }^{1}$ Constituição Federal do Brasil de 1988, Lei de Diretrizes e Bases da Educação Nacional de 1996, Plano Nacional de Educação de 2001 e a Lei no 11.494 de 2007 do Fundo de Manutenção e Desenvolvimento da Educação Básica e de Valorização dos Profissionais da Educação (FUNDEB).
} 
associado a outros termos que produzem expressões do tipo: melhoria da qualidade, sem prejuízo da qualidade, expansão com qualidade, atendimento de qualidade ou elevando a qualidade geral da educação, referências que, a partir das considerações de Casassus (2007), podem ser classificadas como conceitos significantes, mobilizadores e amplamente utilizados na sociedade, porém, ambíguos. A ambiguidade a que se refere este último autor se deve ao fato de que, frente às inúmeras possibilidades de utilização do termo qualidade, este acaba por não explicar, não definir e, por conseguinte, não estabelecer uma definição precisa.

Dessa feita, frente a uma indefinição legal e teórica quanto ao conceito de qualidade educacional ou, ainda, frente às muitas possibilidades de utilização e interpretação, ganha força, por diferentes motivos, entre os profissionais da educação mais ligados à escola pública de educação básica, a noção de que a qualidade educacional é expressa nos resultados das avaliações externas em larga escala, ou seja, em um índice construído a partir do desempenho de parte dos alunos da escola em testes padronizados referentes a apenas dois (2) componentes curriculares e nas taxas de fluxo escolar de todos os alunos dessa escola. Silva (2008) define essa situação como a narrativa instrumental da qualidade na educação, uma vez que, nessas condições, a finalidade da escola é reduzida ao cumprimento de metas que pouco, ou muito pouco, expressam do trabalho realizado pela escola.

Ao estabelecer, por força da lei, o IDEB como conceito de qualidade da educação básica nacional o PNE 2014-2024 (BRASIL, 2014) desestimula - ao menos durante sua vigência - a necessária continuidade do debate acadêmico e legal sobre o conceito de qualidade da educação básica nacional.

\subsection{Qualidade da educação básica nacional a partir do PNE 2014-2024}

Em 25 de junho de 2014, a presidente da República sancionou a Lei no 13.005 (BRASIL, 2014) que aprova, em cumprimento ao artigo 214 da Constituição Federal (BRASIL, 1988), o PNE 20142024 composto por dez (10) diretrizes, vinte (20) metas e duzentas e cinquenta e quatro (254) estratégias. Com o auxílio de um dicionário (FERREIRA, 1999) é possível compreender que uma diretriz corresponde a um conjunto de instruções ou indicações para se tratar e levar a termo uma ação, um negócio; uma meta corresponde a um alvo, a uma mira, a um objetivo e estratégia, por sua vez, corresponde à arte de aplicar os meios disponíveis à consecução de objetivos específicos. Em outras palavras, é possível afirmar que o PNE 2014-2024 (BRASIL, 2014) é um plano de ação, imposto legalmente em 2014, com o objetivo de atender, até 2024, necessidades do campo educacional identificadas e descritas, pelo menos, desde 1988.

Sem minimizar outras diretrizes, metas e estratégias presentes no PNE 2014-2024 (BRASIL, 2014) a contextualização de qualidade da educação básica nacional proposta neste item toma por referência a diretriz IV do artigo $2^{\circ}$, os artigos $5^{\circ}$ e $11^{\circ}$ e a meta 7 e suas estratégias $7.2,7.6,7.9$, e 7.36 por estabelecerem metas, expressas em números, a serem cumpridas ou por associarem a obtenção de algum benefício imediato para a escola ou para seus profissionais em função do cumprimento destas metas.

À diretriz IV do artigo $2^{\circ}$ que trata da melhoria da qualidade da educação associamos arbitrariamente 0 artigo $5^{\circ}$ que estabelece as instâncias responsáveis pelo monitoramento contínuo e por avaliações periódicas quanto à execução do PNE e o cumprimento de suas metas e o artigo $11^{\circ}$ que constitui o "Sistema Nacional de Avaliação da Educação Básica como fonte de informação para a qualidade da educação básica e para a orientação das políticas públicas desse nível de ensino" (BRASIL, 2014, p. 2).

No que se refere ao artigo $5^{\circ}$ e às instâncias que apresenta - o Ministério da Educação (MEC), a Comissão de Educação da Câmara dos Deputados, a Comissão de Educação, Cultura e Esporte 
do Senado Federal e o Conselho Nacional de Educação (CNE) e Fórum Nacional de Edu cação - é possível inferir que representantes de diferentes e importantes instituições e segmentos da sociedade e do campo educacional ocupam papel de destaque no monitoramento contínuo da execução do PNE. Todavia, a partir do exposto no item anterior, tornar-se-ia uma incógnita identificar o parâmetro de qualidade da educação básica nacional a ser utilizada pelas referidas instâncias.

O artigo $11^{\circ}$ elimina esta incógnita ao definir que o Sistema Nacional de Avaliação da Educação Básica (SAEB), coordenado pela União, em colaboração com os Estados, o Distrito Federal e os municípios, constituirá fonte de informações para a avaliação da qualidade da educação básica e para a orientação das políticas públicas desse nível de ensino. Estabelece também, que a qualidade da educação básica nacional será aferida e expressa em índices como o IDEB que agregam indicadores de rendimento escolar obtidos em avaliações nacionais e nas taxas de aprovação apurados pelo censo escolar. Por fim, atribui ao Instituto Nacional de Estudos e Pesquisas Educacionais Anísio Teixeira (INEP) a elaboração e o cálculo do IDEB.

Os últimos parágrafos expõem uma legislação federal que estabelece a melhoria da qualidade da educação como uma de suas diretrizes, que define os responsáveis pelo monitoramento contínuo e avaliações periódicas da execução da referida diretriz e estabelece como será aferida e como serão divulgados os resultados destas ações. Contudo, é a meta 7 que sintetiza todo este itinerário, ao definir as médias nacionais a serem atingidas para o IDEB em suas próximas edições. Todavia, a simples utilização de médias - ainda mais nacionais para um país de dimensões continentais - é preocupante principalmente com base no que apresentam Darling-Hammond e Ascher (2006, p. 26) ao destacarem que "se as médias escondem informações individuais dos estudantes, então serão inválidas quaisquer interpretações baseadas em tendências da média". Se tal afirmação é válida para o aluno individualmente, também será válida para a escola individualmente. De todo modo, a Tabela 1 apresenta as metas das médias previstas.

Tabela 1 - Metas IDEB previstas para cada etapa educacional

\begin{tabular}{ccccc}
\hline Etapa Educacional & \multicolumn{4}{c}{ Meta Prevista } \\
\cline { 2 - 5 } & $\mathbf{2 0 1 5}$ & $\mathbf{2 0 1 7}$ & $\mathbf{2 0 1 9}$ & $\mathbf{2 0 2 1}$ \\
\hline Anos iniciais do ensino fundamental & 5,2 & 5,5 & 5,7 & 6 \\
Anos finais do ensino fundamental & 4,7 & 5 & 5,2 & 5,5 \\
Ensino Médio & 4,3 & 4,7 & 5 & 5,2 \\
\hline
\end{tabular}

Fonte: Elaborado pelo autor a partir de Brasil (2014).

A utilização de uma tabela para a exposição das metas previstas para cada edição do IDEB contribui para que o leitor tenha uma visão do cenário da educação básica como um todo e pode induzi-lo a pensar na hipótese de que o cumprimento das metas previstas possa ser entendido como tarefa não muito difícil, visto que corresponde apenas a um avanço de 0,8 ou 0,9 numa escala que varia de 0 a 10 para um período de oito (8) anos.

O objetivo deste artigo não é o de analisar os índices obtidos em edições anteriores ou as metas estabelecidas para as próximas edições, porém, ao acrescentarmos às informações da Tabela 1 os índices obtidos nas edições anteriores, a hipótese de tarefa não muito difícil não se sustenta. A Tabela 2 apresenta o agrupamento de índices de edições anteriores com as metas previstas para as próximas edições. 
Tabela 2 - IDEB observado e metas previstas para cada etapa educacional

\begin{tabular}{ccccccccccc}
\hline Etapa Educacional & \multicolumn{4}{c}{ IDEB Observado } & \multicolumn{4}{c}{ Meta Prevista } \\
\cline { 2 - 11 } & 2005 & 2007 & 2009 & 2011 & 2013 & 2015 & 2017 & 2019 & 2021 \\
\hline Anos iniciais do ensino fundamental & 3,8 & 4,2 & 4,6 & 5 & 5,2 & 5,2 & 5,5 & 5,7 & 6 \\
Anos finais do ensino fundamental & 3,5 & 3,8 & 4 & 4,1 & 4,2 & 4,7 & 5 & 5,2 & 5,5 \\
Ensino Médio & 3,4 & 3,5 & 3,6 & 3,7 & 3,7 & 4,3 & 4,7 & 5 & 5,2 \\
\hline
\end{tabular}

Fonte: Elaborado pelo autor a partir de INEP (2014).

Uma simples análise das informações apresentadas na Tabela 2 permite identificar que o IDEB observado, principalmente nas duas últimas edições, avançou pouco em valores absolutos e que as metas previstas para as próximas edições sugerem dificuldades maiores para seu cumprimento, visto que para atingir os valores absolutos previstos seriam necessários crescimentos maiores, em valores absolutos, do que os observados nas duas últimas edições, o que nos leva a analisar as estratégias propostas para tal.

Dentre as vinte (20) metas descritas no PNE 2014-2024 (BRASIL, 2014) a meta 7: "fomentar a qualidade da educação básica em todas as etapas e modalidades, com melhoria do fluxo escolar e da aprendizagem de modo a atingir as seguintes médias nacionais para o IDEB (BRASIL, 2014, p. 7)" é a que apresenta a maior quantidade de estratégias, em um total de, trinta e seis (36), em que cada uma possibilita o estabelecimento de diversas hipóteses quanto a sua contribuição para o cumprimento das metas IDEB previstas e, consequentemente, para a melhoria da qualidade da educação, uma vez que abarcam questões relacionadas ao currículo, à gestão de recursos, ao uso de novas tecnologias, ao atendimento a clientelas diferenciadas entre outros.

Todavia, destaco que as estratégias como a 7.2 e a 7.9 que estabelecem metas, expressas em indicadores, a serem cumpridas; ou a estratégia 7.6 que associa a oferta de assistência técnica ou financeira ao cumprimento destas metas ou a estratégia 7.36 que valoriza o mérito do corpo docente a partir da melhora no desempenho do IDEB podem resultar em prejuízos na busca por uma educação de qualidade, uma vez que, pesquisas apontam há muito para os riscos de se balizar toda e qualquer política educacional exclusivamente em indicadores estatísticos.

Inicialmente destaca-se o trabalho de Freitas (2007) ao afirmar que o uso inadequado de indicadores estatísticos no campo educacional sustenta políticas que ocultam a má qualidade educacional de nossas escolas e penaliza os alunos, simplesmente os mantendo por um período maior de tempo nas escolas, sem conferir-lhes muita coisa em termos de aprendizagem efetiva, por exemplo. O trabalho de Gatti (2009) corrobora os achados de Freitas (2007), uma vez que aponta limitações observadas em gestores educacionais - personagens fundamentais na efetivação de políticas educacionais na escola - no que tange ao entendimento e utilização das informações presentes nos boletins de resultados das avaliações externas. Passados mais alguns anos Blasis, Falsarella e Alavarse, (2013) constatam que tal cenário permanece inalterado.

A este cenário somam-se as estratégias 7.2, 7.9, 7.6 e 7.36, citadas anteriormente, que para sua efetivação necessitam fundamentalmente da participação do gestor escolar. Vejamos:

A estratégia 7.2 enfatiza a necessidade de assegurar que:

a) no quinto ano de vigência deste PNE, pelo menos $70 \%$ (setenta por cento) dos (as) alunos (as) do ensino fundamental e do ensino médio tenham alcançado nível suficiente de aprendizado em relação aos direitos e objetivos de aprendizagem e desenvolvimento de seu ano de estudo, e $50 \%$ (cinquenta por cento), pelo menos, o nível desejável; 
b) no último ano de vigência deste PNE, todos os (as) estudantes do ensino fundamental e do ensino médio tenham alcançado nível suficiente de aprendizado em relação aos direitos e objetivos de aprendizagem e desenvolvimento de seu ano de estudo, e 80\% (oitenta por cento), pelo menos, o nível desejável. (BRASIL, 2014, p. 7).

Ao cotejar o cenário descrito anteriormente pelas produções de Freitas (2007), de Gatti (2009) e de Blasis, Falsarella e Alavarse, (2013) com a solicitação da estratégia 7.2 é possível inferir que o gestor escolar encontra-se em uma situação em que por um lado é pressionado para o cumprimento de metas e por outro lado ainda apresenta muitas dificuldades para interpretar e utilizar de modo eficiente estas metas.

A estratégia 7.9 destaca a necessidade de

[...] orientar as políticas das redes e sistemas de ensino, de forma a buscar atingir as metas do Ideb, diminuindo a diferença entre as escolas com os menores índices e a média nacional, garantindo equidade da aprendizagem e reduzindo pela metade, até o último ano de vigência deste PNE, as diferenças entre as médias dos índices dos Estados, inclusive do Distrito Federal, e dos Municípios. (BRASIL, 2014, p. 7).

Ao receber as metas IDEB como parâmetro de qualidade, ou melhor, como alvos a serem alcançados o gestor escolar não tem outra opção que não seja a de buscar o cumprimento destas metas independente daquilo que considere qualidade educacional ou das peculiaridades de sua escola ainda mais porque a utilização da média oculta todas as inúmeras peculiaridades de cada escola.

A estratégia 7.6 estabelece a necessidade de "associar a prestação de assistência técnica financeira à fixação de metas intermediárias, nos termos estabelecidos, conforme pactuação voluntária entre os entes, priorizando sistemas e redes de ensino com IDEB abaixo da média nacional (BRASIL, 2014, p. 7)", ao passo que a estratégia 7.36 propõe "estabelecer políticas de estímulo às escolas que melhorarem o desempenho no IDEB, de modo a valorizar o mérito do corpo docente, da direção e da comunidade escolar (BRASIL, 2014, p. 9)".

O cenário completo, ou seja, o gestor escolar que apresenta um conhecimento limitado sobre a utilização dos indicadores presentes nos relatórios das avaliações externas em larga escala e ainda pressionado para obtenção de metas pautadas em indicadores estatísticos, no caso o IDEB, tem produzido desdobramentos como os descritos a seguir.

Bonamino e Souza (2012) afirmam que a busca exacerbada pelo cumprimento das metas, no caso expressas nos indicadores estatísticos, estabelecidas pelas avaliações externas em larga escala alterou significativamente o currículo e, consequentemente, as práticas escolares. O trabalho de Gesqui (2012) constata que as práticas escolares mais efetivadas nas escolas públicas paulistas com o objetivo de cumprir metas estabelecidas para os indicadores estatísticos de qualidade educacional e, por conseguinte para a obtenção de premiação financeira por parte dos profissionais da educação, limitam-se à realização de grande quantidade de exames simulados com o objetivo de treinar os alunos para as avaliações externas e na elaboração e aperfeiçoamento de instrumentos que possibilitem a manutenção dos alunos dentro do limite legal de ausências com o objetivo de promovê-lo para a série seguinte, tendo por base o registro de sua frequência escolar.

Certamente as políticas educacionais devem fazer uso dos indicadores estatísticos, porém não se podem jogar todas as fichas única e exclusivamente nos mesmos, haja vista o relato de Ravitch (2011) quanto aos muitos aspectos negativos, evidenciados após décadas da utilização desenfreada dos indicadores estatísticos na definição e efetivação das políticas educacionais americanas. Vale ressaltar que o cenário do campo educacional americano, descrito pela autora, em muito se assemelha ao atual cenário do campo educacional brasileiro descrito neste artigo, sto é, uma sanha em se cumprir as diretrizes, metas e estratégias propostas pelo atual PNE, 
isem o conhecimento suficiente se tais ações contribuirão de fato para a melhoria da qualidade da educação básica nacional, ou, nas palavras de Ravitch (2011, p. 18) "tudo parecia fazer sentido, mas havia pouca evidência empírica, apenas promessa e esperança”.

\section{3 | CONSIDERAÇÕES FINAIS}

A utilização de indicadores estatísticos no campo educacional tem ocupado, principalmente a partir das duas últimas décadas, papel central na definição de políticas educacionais de nosso país, em especial com a justificativa de contribuir, direta ou indiretamente, para a melhoria da qualidade de ensino, tanto que seus desdobramentos são facilmente perceptíveis em diferentes âmbitos do campo: a definição de programas e projetos educacionais bem como a destinação de recursos financeiros pelos órgãos centrais; a seleção de práticas escolares e de modelos de gestão escolar; os procedimentos utilizados em sala de aula são exemplos desses desdobramentos.

Os referidos indicadores têm sido difundidos de tal forma no campo educacional que dificilmente são questionados, ao menos pelo grande público, quanto à sua validade, precisão e, principalmente, se, apesar de toda a tecnologia de que faz uso, realiza aquilo a que é oficialmente proposto, ou seja, contribuir efetivamente para a melhoria da qualidade da educação e fornecer informações que orientem políticas educacionais.

Algumas das hipóteses para a falta de críticas quanto à elaboração, à utilização ou aos resultados produzidos por esses indicadores podem estar relacionadas justamente à necessidade de conhecimentos matemáticos específicos, a indisponibilidade de tempo para uma análise detaIhada ou simplesmente pelo fato de que, deliberadamente, foram atrelados, aos tais indicadores, mecanismos de premiação e punição para os envolvidos, que os transformaram em objetos de desejo e temor, independentemente do que expressem.

A falta de críticas adensadas por parte dos leigos ao estabelecimento do IDEB como parâmetro de qualidade da educação nacional é, até certo ponto, compreensível pelo exposto anteriormente e pelos modos como é realizada sua divulgação nos meios de comunicação. Contudo, como compreender o silêncio quase total observado nos profissionais da educação e seus representantes, no que se refere ao fato de o IDEB, desconsiderando toda a produção acadêmica e legal sobre qualidade educacional e definir o que é qualidade da educação básica nacional?

É possível argumentarmos que as estratégias propostas pela meta 7 expressam necessidades e elementos identificados nas referidas produções que antecedem o PNE 2014-2024, porém, o IDEB como parâmetro de qualidade da educação básica é um fato, ao passo que as necessidades e elementos são expectativas que podem ou não serem transformadas em realidade, donde surge uma questão: se, de fato, estes elementos e necessidades são centrais para se alcançar uma meta e, por conseguinte, obter uma educação de qualidade. Assim, por que não implementar políticas educacionais com o objetivo de contemplar tais estratégias e, posteriormente, a aferição da qualidade educacional por meio de um indicador comum?

As poucas produções utilizadas para cotejar o proposto nas estratégias da meta 7 com o que se tem observado no cotidiano das escolas possibilitam vislumbrar hipóteses sobre possíveis desdobramentos do estabelecimento do IDEB, como parâmetro de qualidade da educação básica. Devem, pois, instigar, ao menos, os profissionais da educação a se manifestarem quanto a essa imposição legal. Chega a ser, no mínimo, questionadora a falta de críticas adensadas ao estabelecimento do IDEB como parâmetro de qualidade da educação básica nacional não apenas pelo que este artigo apresenta, mas, e principalmente por tudo que o campo educacional brasileiro tem produzido nos últimos anos. 


\section{Referências}

BALL, S. Performatividade, privatização e o pós-Estado do bem estar. Educação e Sociedade, Campinas, v. 25, n. 89, p.1105-1126, 2004. Disponível em: <http://www. scielo.br/pdf/es/v25n89/22613.pdf>. Acesso em: 20 ago. 2015.

BEISIEGEL, C. R. A qualidade do ensino da escola pública. Brasília: Liber Livro, 2006.

BLASIS, E. de; FALSARELLA, A. M.; ALAVARSE, O. M. Avaliação e aprendizagem: avaliações externas: perspectivas para a ação pedagógica e gestão do ensino. São Paulo: CENPEC; Fundação Itaú Social, 2013.

BONAMINO, A.; MARTÍNEZ, S. A. Diretrizes e parâmetros curriculares nacionais para o ensino fundamental. Educação e Sociedade, Campinas, v. 23 , n. 80 , p. 368 385, 2002. Disponível em: <http://www.scielo.br/pdf/es/ v23n80/12937.pdf>. Acesso em: 21 jun. 2015.

BONAMINO, A.; SOUZA, S. Z. Três gerações de avaliação da educação básica no Brasil: interfaces com o currículo da-na escola. Educação e Pesquisa, São Paulo, v. 38, n. 2, p. 373-388, 2012. Disponível em: <http:/l www.scielo.br/pdf/ep/v38n2/aopep633.pdf>. Acesso em: 20 ago. 2015.

BRASIL. Constituição (1988). Constituição da República Federativa do Brasil. Brasília, DF: Senado Federal, 1988.

Lei $n^{\circ}$ 9.394, de 20 de dezembro de 1996. Estabelece as diretrizes e bases da educação nacional. Diário Oficial da União. Brasília, DF, 23 dez. 1996. Disponível em: <http://www.planalto.gov.br/ccivil_03/Leis/ L9394.htm>. Acesso em: 12 jun. 2014.

Lei $n^{\circ} 13.005$, de 25 de junho de 2014. Aprova o Plano Nacional de Educação - PNE e dá outras providências. Diário Oficial da União. Brasília, DF, 26 jun. 2014. Disponível em: <http://www.planalto.gov.br/ ccivil_03/_ato2011-2014/2014/lei//13005.htm>. Acesso em: 12 set. 2015.

CARVALHO, M. P. de. Estatísticas de desempenho escolar: o lado avesso. Educação e Sociedade, Campinas, n. 77, p. 231-252, 2001. Disponível em: <http://www.scielo.br/pdf/es/v22n77/7052.pdf>. Acesso em: 10 jun. 2015.

CASASSUS, J. A escola e a desigualdade. Tradução Lia Zatz. 2. ed. Brasília: Liber Livro Editora, 2007.
DARLING-HAMMOND, L.; ASCHER, C. Construindo sistemas de controle em escolas urbanas. Tradução de Andréa Barbosa Gouveia e Ângelo Ricardo de Souza. Estudos em Avaliação Educacional, São Paulo, v. 17, n. 35, p. 7-48, set./dez. 2006. Disponível em: $<$ http://www.fcc.org.br/pesquisa/publicacoes/eae/arquivos/1338/1338.pdf>. Acesso em: 8 maio 2014.

DOURADO, L. F. Políticas e gestão da educação básica no Brasil: limites e perspectivas. Educação e Sociedade, Campinas, v. 28, n. 100, p. 921-946, 2007. Disponível em: $\quad<$ http://www.scielo.br/pdf/es/v28n100/a1428100. pdf>. Acesso em: 12 ago. 2015.

DOURADO, L. F.; OLIVEIRA, J. F. A qualidade da educação: perspectivas e desafios. Cadernos Cedes, Campinas, v. 29, n. 78, p. 201-215, 2009. Disponível em: <http://www.scielo.br/pdf/ccedes/v29n78/v29n78a04>. Acesso em: 21 ago. 2015.

FERREIRA, A. B. H. Aurélio século XXI: o dicionário da língua portuguesa. Rio de Janeiro: Nova Fronteira, 1999.

FREITAS, L. C. Eliminação adiada: o ocaso das classes populares no interior da escola e a ocultação da (má) qualidade de ensino. Educação e Sociedade, Campinas, v. 28, n. 100 - Especial, p. 965-987, 2007. Disponível em: $\quad<$ ttp://www.scielo.br/pdf/es/v28n100/a1628100. pdf>. Acesso em: 25 jun. 2015.

GATTI, B. A. Avaliação de sistemas educacionais no Brasil. Sísifo - Revista de Ciências da Educação, Lisboa, n. 9, p.7-17, 2009.

GESQUI, L. C. A importância dos resultados das avaliações educacionais em larga escala na definição de práticas escolares. In: ENCONTRO NACIONAL DE DIDÁTICA E PRÁTICAS DE ENSINO, 16., 2012, Campinas. Anais... Campinas: UNICAMP, 2012. Disponível em: <http://www.infoteca.inf.br/endipe/smarty/templates/arquivos_template/upload_arquivos/acervo/docs/2193b. pdf>. Acesso em: 16 ago. 2015.

GUSMÃO, J. B. B. de. Qualidade da educação no Brasil: consenso e diversidade de significados. Dissertação (Mestrado em Educação)- Faculdade de Educação, Universidade de São Paulo, São Paulo, 2010.

INSTITUTO NACIONAL DE ESTUDOS E PESQUISAS EDUCACIONAIS ANÍSIO TEIXEIRA. Índice de Desenvolvimento da Educação Básica - IDEB: resultados e metas. Brasília, DF, 2014. Disponível em: <http://ideb. inep.gov.br/resultado/>. Acesso em: 15 fev. 2015. 
OLIVEIRA, D. A. Educação básica: gestão do trabalho e da pobreza. Petrópolis: Vozes, 2000.

OLIVEIRA, R. P. de. Da universalização do ensino fundamental ao desafio da qualidade: uma análise histórica. Educação e Sociedade, Campinas, v. 28, n. $100-$ Especial, p. 661-690, out. 2007. Disponível em: <http:// www.scielo.br/pdf/es/v28n100/a0328100.pdf>. Acesso em: 15 jun. 2015.

Estado e política educacional no Brasil: desafios do século XXI. 2006. 161f. Tese (Livre docência)Faculdade de Educação, Universidade de São Paulo, São Paulo, 2006.

OLIVEIRA, R. P.; ADRIÃO, T. (Org.). Gestão, financiamento e direito à educação: análise da Constituição Federal e da LDB. São Paulo: Xamã, 2007.

RAMOS, M. N. O desafio da qualidade da educação básica. Jornal da Sociedade Brasileira de Química, v. 21, n. 3, 2010. Disponível em: <http:// www.scielo.br/scielo.php?script=sci_arttext\&pid=S0103-50532010000300001>. Acesso em: 5 jun. 2015.

RAVITCH, D. Vida e morte do grande sistema escolar americano: como os testes padronizados e o modelo de mercado ameaçam a Educação. Tradução de Marcelo Duarte. Porto Alegre: Sulina, 2011.
SHIROMA, E. O.; MORAES, M. C. M..; EVANGELISTA, O. Política educacional. Rio de Janeiro. DP\&A, 2004.

SILVA, V. G. da. Por um sentido público da qualidade da educação. 2008. 120f. Tese (Doutorado em Educação)Faculdade de Educação, Universidade de São Paulo, São Paulo, 2008.

SOUZA, D. B.; FARIA, L. C. M. Reforma do estado, descentralização e municipalização do ensino no Brasil: a gestão política dos sistemas públicos de ensino pós LDB 9.394/96. Ensaio: Avaliação e Políticas Públicas em Educação, Rio de Janeiro, v. 12, n. 45, p. 925-944, 2004. Disponível em: <http://www.scielo.br/pdf/ensaio/ v12n45/v12n45a02>. Acesso em: 10 jul. 2015.

TOMMASI, L.; WARDE, M.; HADDAD, S. O Banco Mundial e as políticas educacionais. São Paulo: Cortez; PUC-SP; Ação Educativa, 1996.

UNESCO. Educação de qualidade para todos: um assunto de direitos humanos. Brasília: UNESCO; OREALC, 2007. 138 p. 